\title{
Microstructure Features and Superplasticity of Extruded, Rolled and SPD-Processed Magnesium Alloys: A Short Review
}

\author{
Abdul Malik ${ }^{1,+}\left(\mathbb{D}\right.$, Umer Masood Chaudry ${ }^{2,+}\left(\mathbb{D}\right.$, Kotiba Hamad $^{3, *}$ and Tea-Sung Jun ${ }^{2, *} \mathbb{(}$ \\ 1 School of Material Science and Engineering, Beijing Institute of Technology, Beijing 100081, China; \\ abdulmalik0001@yahoo.com \\ 2 Department of Mechanical Engineering, Incheon National University, Incheon 22012, Korea; umer@skku.edu \\ 3 School of Advanced Materials Science \& Engineering, Sungkyunkwan University, Suwon 16419, Korea \\ * Correspondence: hamad82@skku.edu (K.H.); t.jun@inu.ac.kr (T.-S.J.) \\ + These authors contributed equally to this work.
}

Citation: Malik, A.; Masood Chaudry, U.; Hamad, K.; Jun, T.-S. Microstructure Features and Superplasticity of Extruded, Rolled and SPD-Processed Magnesium Alloys: A Short Review. Metals 2021, 11, 1766. https://doi.org/10.3390/ met11111766

Academic Editor: Eric Hug

Received: 24 September 2021

Accepted: 30 October 2021

Published: 3 November 2021

Publisher's Note: MDPI stays neutral with regard to jurisdictional claims in published maps and institutional affiliations.

Copyright: (c) 2021 by the authors. Licensee MDPI, Basel, Switzerland. This article is an open access article distributed under the terms and conditions of the Creative Commons Attribution (CC BY) license (https:/ / creativecommons.org/licenses/by/ $4.0 /)$.

\begin{abstract}
In this study, an overview of microstructure features such as grain size, grain structure, texture and its impact on strain rate sensitivity, strain hardening index, activation energy and thermal stability for achieving superplasticity of $\mathrm{Mg}$ alloys are presented. The deformation behavior under different strain rates and temperatures was also elaborated. For high elongation to fracture grain boundary sliding, grain boundary diffusion is the dominant deformation mechanism. In contrast, for low-temperature and high strain rate superplasticity, grain boundary sliding and solute drag creep mechanism or viscous glide dislocation followed by GBS are the dominant deformations. In addition, the results of different studies were compared, and optimal strain rate and temperature were diagnosed for achieving excellent high strain rate superplasticity.
\end{abstract}

Keywords: grain size; superplasticity; elongation to fracture; thermal stability; texture

\section{Introduction}

The use of lightweight materials is a convenient way to reduce carbon dioxide emissions and increase fuel efficiency so that their use can be enhanced as a structural material in automobile and military industries. Magnesium $(\mathrm{Mg})$ alloys are prospective lightweight (density 1.78 $\mathrm{g} / \mathrm{cm}^{3}$ ) materials and possess a high strength-to-weight ratio and high machinability [1-3]. However, these alloys are comprised of hexagonal close packed (HCP) crystal structures and have an inadequate c/a ratio [4-10]. The complex shape component of thermomechanical-processed wrought alloys cannot be designed due to very complex deformation (different mode of twinning, twinning variants, twinning morphology and twinning types [11]) and limited-slip activity under ambient temperature loading. Therefore, elevated temperatures $\left(250-450{ }^{\circ} \mathrm{C}\right.$ ) are required to process $\mathrm{Mg}$ alloys. Critical resolved shear stresses (CRSS) are very low for basal slip and extension twinning in early stages of deformation [12], whilst the CRSS of non-basal slip is significantly reduced under high-temperature loading; therefore, multiple slip activity and no twinning activity are beneficial for the smooth processing of $\mathrm{Mg}$ alloys [13].

Superplasticity is intriguing for industrial and academic development due to the ability to manufacture complicated components. It can also produce uniform elongation without strain hardening, pre-mature failure and necking. Therefore, tensile loading under different strain rates and temperatures has been conducted to achieve superplasticity. Superplasticity is correlated with microstructure features such as grain size, grains morphology, precipitates type and their dissolution temperature and texture. Furthermore, the most important parameters for superplasticity, strain rate sensitivity (m-value) and hardening index ( $n$-value) are highly dependent on the aforementioned parameters. These feathers are very significant for achieving the superplasticity of $\mathrm{Mg}$ alloys. The rate of the deformation (activation energy (Q-value)) can be controlled by optimizing temperature 
and strain rate. Different studies revealed different values; however, the value close to grain boundary self-diffusion $(92 \mathrm{KJ} / \mathrm{mol})$ might be considered most feasible for superplasticity, while the value between 110 and $135 \mathrm{Kj} / \mathrm{mol}$ is related to the lattice self-diffusion of $\mathrm{Mg}$ alloys. Therefore, high strain rate and low temperature are the requirements for industrial manufacturing, which can save time and energy. This low temperature and high strain rate can change the rate of deformation, and thus change the m-value, $\mathrm{Q}$-value and $n$-value. Therefore, possible deformation mechanisms and superplasticity are critical issues at both low and high temperatures and strain rates. Thus, this study sheds light on the microstructure features of different fabricated $\mathrm{Mg}$ alloys and their response/deformation to facilitate superplasticity.

\section{Grain Size and $m$-Value}

To date, different thermomechanical processing techniques have been employed to achieve a microstructure comprised of equiaxed fine grains. Among them, equal channel angular pressing (ECAP) and friction stir processing (FSP) can provide grain size up to a nano-meter order. However, the final limited dimension of the product is justified for some specific applications. Apart from them, extrusion and rolling are vastly employed to achieve fine grain structure; nevertheless, a single pass of extrusion or rolling barely produces a fully refined nano-size grain structure. It is believed that the alloys that possess a grain size $<10 \mu \mathrm{m}$ exhibit superior superplasticity, while those with grain size $>10 \mu \mathrm{m}$ do not exhibit superplasticity. Usually, grain size is a key parameter that is highly linked with the m-value. For perfect superplastic behavior, the m-value should be greater than 0.4 while the $n$-value should be $\leq 2.5$. It is commonly observed that the alloys comprised of bi-modal grain size show $\mathrm{m}$-values $\sim 0.3$ while those having refined grains of a nano-meter have m-values greater than or equal to 0.5. Chaudry et al. [14] fabricated an AZ31-0.5Ca $\mathrm{Mg}$ alloy and calculated an $\mathrm{m}$-value $\sim 0.31$ and reported superplastic behavior at a strain rate of $10^{-3} \mathrm{~s}^{-1}$. Similarly, AZ31 Mg alloy has a grain size $\sim 7 \mu \mathrm{m}$; however, grain structure was much different than AZ31-0.5Ca. As such, the m-value was different. Malik et al. [15] also synthesized a fine grain structured extruded ZK61 Mg alloy and reported an m-value of 0.51 and revealed that the alloy exhibited superplasticity at a higher temperature of $400{ }^{\circ} \mathrm{C}$. Álvarez-Leal et al. [16] studied the superplasticity in an extruded ZK30 Mg alloy; the microstructure was comprised of bi-modal grain structure, i.e., small fine grains (1$5 \mu \mathrm{m})$ and large grains $(30 \mu \mathrm{m})$. They reported $n$-value $\sim 2.6(\mathrm{~m}=1 / n, \sim 0.38)$ at higher temperatures and a transition from 2 to 5 at higher strain rates. The $\mathrm{m}$-values have different values for all alloys due to differences in grain size regardless of other microstructure features such as the thermal stability of microstructure (precipitates and grain size).

Figure 1 is a statistical graph of grain size vs. strain rate sensitivity. The decrease in the grain size increases the $\mathrm{m}$-value of the alloys ( $\mathrm{m} 0.5$ ), which enables superplasticity. The $\mathrm{m}$ value is also strain rate dependent. Increasing the strain rate decreases the m-value, which further leads to pre-mature failure and restricts superplasticity. Thus, precise temperature and strain rate for extraordinary superplasticity should be adopted for smooth processing. After a brief analysis, the following key points related to the grain size and m-value can be concluded.

- The grain size $\geq 10 \mu \mathrm{m}$ is not recommended for excellent superplasticity;

- With the increase in grain size, m-value was decreased, whilst with the decrease in the grain m-value was increased;

- At low temperature and high strain rate, the m-value was decreased and restricted superplasticity. 


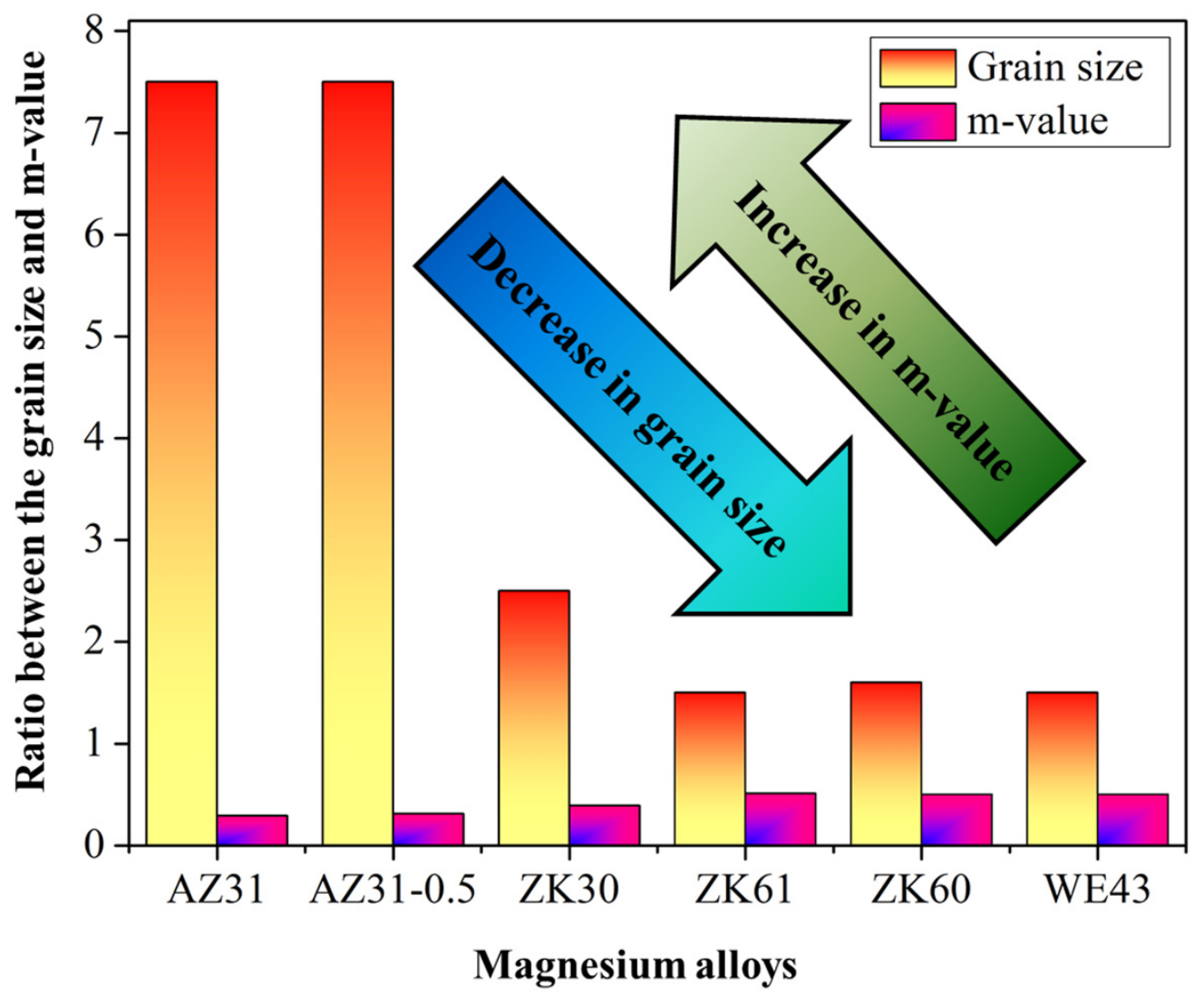

Figure 1. The statistical graph of grain size and m-value of given alloys [14-18] (the grain size of ZK30 Mg alloy was 1-5 $\mathrm{m}$ and $30 \mu \mathrm{m}$; however, for the graphical presentation, we use an average of $2.5 \mu \mathrm{m})$.

\section{Elongation to Fracture and Deformation Mechanism}

It is obvious that the $\mathrm{m}$-value is the main parameter for determining superplasticity; however, the 2nd significant parameter is elongation to fracture. Ruano et al. [19] reported an elongation to fracture of $312 \%$ under a temperature of $450{ }^{\circ} \mathrm{C}$ in a WE43 $\mathrm{Mg}$ alloy, based on a grain size of $150 \mu \mathrm{m}$ and an m-value $\sim 3$, this elongation to fracture is extraordinary. They also proposed that the deformation was mediated by the solute drag creep mechanism. Hua et al. [20] reported GBS and solute segregation-assisted superplasticity $(\sim 410 \%)$ in a low-alloyed Mg-Zn-Ca-Sn-Mn alloy. Kandalam et al. [21] fabricated a multiaxial forged WE43 Mg alloy and obtained a grain size of $6 \mu \mathrm{m}$ and reported an elongation to fracture $\sim 470 \%$ at a temperature of $375^{\circ} \mathrm{C}$ under a very low strain rate of $0.0003 \mathrm{~s}^{-1}$. Malik et al. [15] reported an elongation to fracture $\sim 400 \%$ in an extruded ZK61 Mg alloy at a strain rate of $0.001 \mathrm{~s}^{-1}$ and a temperature of $400{ }^{\circ} \mathrm{C}$. In another study, Chaudry et al. [14] reported an elongation to fracture of $320 \%$ of a strip-casted AZ31-0.5 Mg alloy under a temperature of $300{ }^{\circ} \mathrm{C}$. Álvarez-Leal et al. [16] reported elongation to fracture $\sim 360 \%$ at a strain rate of $0.01 \mathrm{~s}^{-1}$ under a temperature of $300^{\circ} \mathrm{C}$. The difference in the elongation to fracture in the aforementioned studies can be attributed to the $\mathrm{m}$-value (Figure 1), i.e., with an increase in the m-value, the elongation to fracture also tends to increase.

Watanabe et al. [16] reported the highest elongation to fracture to be $>1000 \%$ in an extruded WE43 Mg alloy. The grain boundary sliding (GBS) phenomenon is reported to be the governing deformation mechanism. Sun et al. [22] reported an elongation to fracture of $972 \%$ in an Mg-Gd-Y-Zn-Zr alloy at a relatively low strain rate of $0.0005 \mathrm{~s}^{-1}$ under a high temperature of $450{ }^{\circ} \mathrm{C}$, and they also proposed that GBS assisted by grain boundary diffusion is the dominant deformation mechanism during elevated temperature loading. 
Regarding high strain rate superplasticity, Kim et al. [17] reported an elongation to fracture $\sim 800 \%$ at a strain rate of $0.01 \mathrm{~s}^{-1}$ under a temperature of $250{ }^{\circ} \mathrm{C}$. They reported that the stress energy was very low during deformation, which assisted them in understanding that the GBS was the governing deformation mechanism. Based on APF topology, they revealed that, in the early stages of deformation (a strain of 0.2 ), the GBS locally acted as a governing deformation and approached $60 \%$ under high strain rate deformation, as shown in Figure 2. This suggests that the GBS is dominant in the early stages of deformation. Vávra et al. [23] fabricated an ultrafine-grained Mg-4Y-3RE alloy through ECAP and reported superplasticity $(\sim 1230 \%)$ at temperatures of $350{ }^{\circ} \mathrm{C}$ and $400{ }^{\circ} \mathrm{C}$ under a strain rate of $0.01 \mathrm{~s}^{-1}$. They also reported excellent superplasticity $(\sim 1000 \%)$ at a very high strain rate of $0.1 \mathrm{~s}^{-1}$ but at a relatively higher temperature of $400{ }^{\circ} \mathrm{C}$.

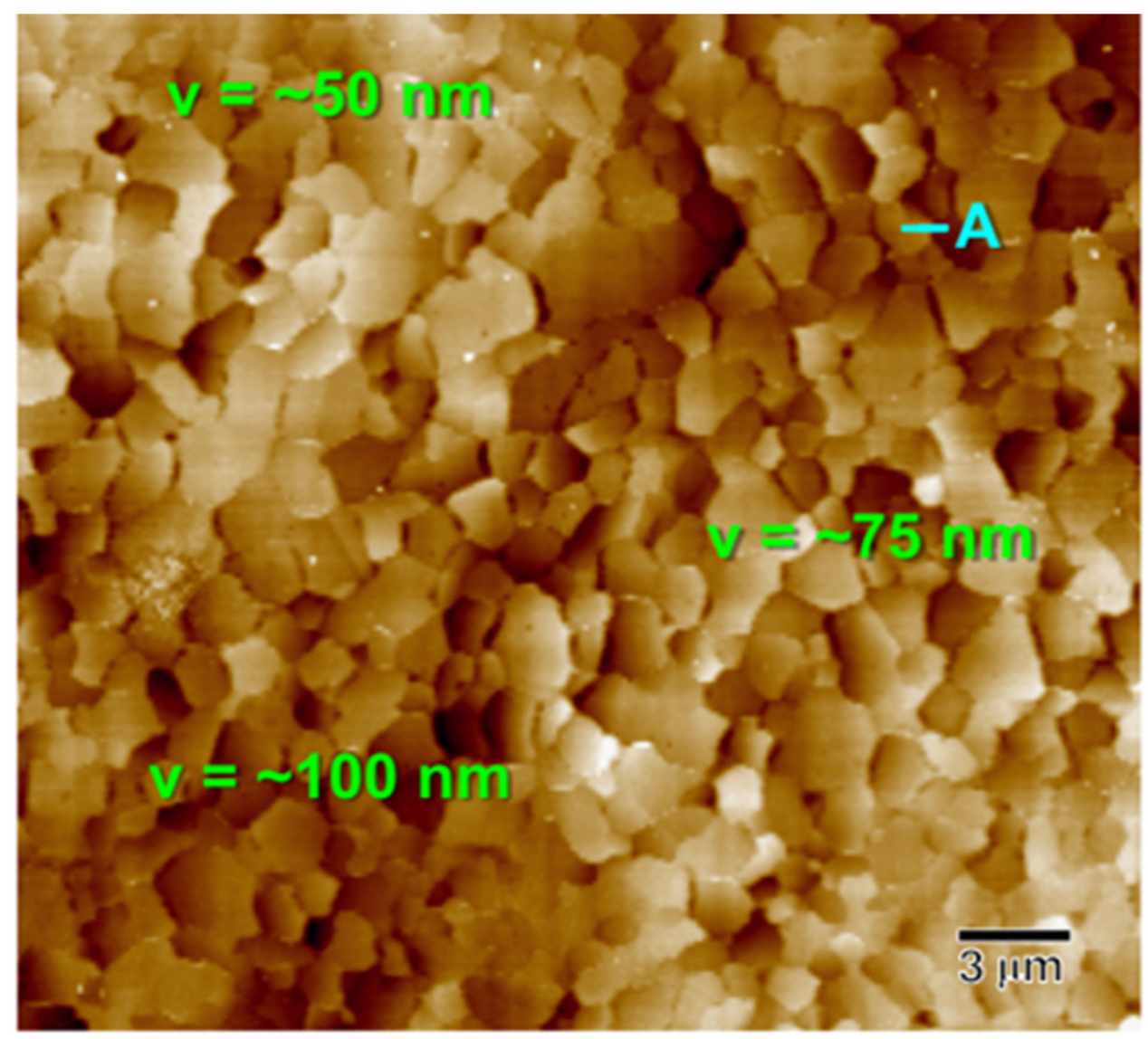

Figure 2. AFM topology of ZK60 Mg alloy under strain rate 0.01 and strain of 0.2 under temperature $250{ }^{\circ} \mathrm{C}$ showing GBS phenomenon [17].

Regarding low-temperature superplasticity, Kim et al. [24,25] reported elongations to fractures of $1000 \%$ and $1021 \%$ (temperature of $280{ }^{\circ} \mathrm{C}$ and strain rate of $0.001 \mathrm{~s}^{-1}$ ) in high ratio differential speed rolling (HRDSR)-processed ZK60 and ZW132 Mg alloys, respectively. This $(1021 \%)$ is the highest value in HRDSR-processed Mg alloy; additionally, they reported that deformation was mediated by GBS. Wang et al. [26] processed an extruded ZK60 $\mathrm{Mg}$ alloy and obtained a homogeneous grain size $\sim 5 \mu \mathrm{m}$ and reported superplasticity $\sim 376-434 \%$ at a low-temperature of $275^{\circ} \mathrm{C}$ and proposed that the deformation was mediated by GBS. Zhou et al. [27] fabricated FSP-processed Mg-Li-Zn alloy and reported elongation to fracture $\sim 369 \%$ at a low-temperature of $200{ }^{\circ} \mathrm{C}$. Figueiredo and Langdon [28] revealed that the deformation was controlled by a viscous glide dislocation mechanism in an ECAPed ZK10 Mg alloy, which exhibited elongation to fracture of $550 \%$ and $750 \%$ at low temperatures $\left(200\right.$ and $\left.250{ }^{\circ} \mathrm{C}\right)$ under a low strain rate of $0.0001 \mathrm{~s}^{-1}$. Similarly, Al- 
Zubaydi et al. [29] reported that the deformation mechanism was glide dislocation creep assisted by GBS under low-temperature loading.

Regarding very low-temperature superplasticity, Xing et al. [30] reported elongation to fracture $\sim 300 \%$ in a multidirectional-forged (MDFed) ultrafine-grained AZ31 Mg alloy at a temperature of $150{ }^{\circ} \mathrm{C}$. Similarly, a high elongation to fracture $~ 800 \%$ was reported in high-pressure torsion (HPT)-processed AZ91 Mg alloy at a low temperature of $150{ }^{\circ} \mathrm{C}$ [31]. Lapovok et al. [32] also presented remarkable superplasticity ( 2040\%) at a low temperature $\left(150{ }^{\circ} \mathrm{C}\right)$ under a strain rate of $0.0003 \mathrm{~s}^{-1}$ of an ECAE + rolled ZK60 Mg alloy. Zhou et al. [27] reported an excellent elongation to fracture (1104\%) at a low temperature of $200{ }^{\circ} \mathrm{C}$ and at a low strain rate of $0.0001 \mathrm{~s}^{-1}$. In another study [33], an ultrafine-grained AZ61 Mg alloy was obtained through MDFed and reported superplasticity at a temperature of $200{ }^{\circ} \mathrm{C}$ under a very low strain rate of $0.000083 \mathrm{~s}^{-1}$.

Langdon and Figuereido [34] reported a remarkable elongation to fracture (3050\%) at a very low strain rate and temperature of $0.0001 \mathrm{~s}^{-1}$ and $200{ }^{\circ} \mathrm{C}$, respectively. According to the literature and Figure 3, this value is the highest ever reported in $\mathrm{Mg}$ alloys. At a similar temperature $\left(200^{\circ} \mathrm{C}\right)$, an elongation to fracture of $\sim 535 \%$ was achieved at a strain rate of $0.0001 \mathrm{~s}^{-1}$ in an HPT-processed ZK60 Mg alloy [35]. Langdon and Figuereido [36] also subjected AZ31 Mg alloy to the ECAP process and achieved elongation to fracture $\sim 1000$ at a temperature of $350-400{ }^{\circ} \mathrm{C}$ and a strain rate of $0.0001 \mathrm{~s}^{-1}$. Regarding the HPT process, Al-Zubaydi et al. [29] reported the highest elongation to fracture of $1308 \%$ at a temperature of $\sim 300{ }^{\circ} \mathrm{C}$ under a low strain rate of $0.0001 \mathrm{~s}^{-1}$, while elongation to fracture $\sim 590 \%$ and $~ 860 \%$ at temperatures of $200{ }^{\circ} \mathrm{C}$ and $300{ }^{\circ} \mathrm{C}$ was also achieved but at a high strain rate of $0.01 \mathrm{~s}^{-1}$, as shown in Figure 3. The deformation mechanism was reported to be GBS; however, for low-temperature superplasticity, they proposed glide dislocation creep assisted by the GBS mechanism. Torbati-Sarraf et al. [37] reported an elongation of $940 \%$ in an HPT-processed ZK60 Mg alloy under a temperature of $250{ }^{\circ} \mathrm{C}$ and a strain rate of $0.0001 \mathrm{~s}^{-1}$. Wang et al. [38] reported superplasticity $\left(680 \% / 0.0005 \mathrm{~s}^{-1}\right)$ of FSP-processed AZ80 Mg alloy at a temperature of $350{ }^{\circ} \mathrm{C}$. The dual-mode superplasticity was reported by Khan and Panigrahi [39] in FSP-processed QE22 Mg alloy, at a temperature of $350{ }^{\circ} \mathrm{C}$ and a low strain rate of $0.003 \mathrm{~s}^{-1}$. The alloy exhibited an elongation to fracture $\sim 850 \%$, whilst, at a higher strain rate of $0.01 \mathrm{~s}^{-1}$ and a higher temperature of $450{ }^{\circ} \mathrm{C}$, an exceptional increase in elongation to fracture of $1630 \%$ was reported.

After a thorough analysis, it can be concluded that:

- The highest elongation to fracture of $>1000 \%$ is reported in extruded WE43 Mg alloy, while the record elongation was 3050 in ECAPed ZK60 Mg alloy. Superplasticity can be achieved at a low temperature of $150{ }^{\circ} \mathrm{C}$ in HPT-processed Mg alloys, and under a high strain rate of $0.1 \mathrm{~s}^{-1}$ in ECAPed Mg alloys;

- The GBS phenomenon assisted by grain boundary diffusion is the dominant deformation at higher elongation to fracture, with an $\mathrm{m}$-value close to 0.5 ; however, both GBS and solute drag creep mechanism, or viscous glide dislocation followed by GBS, are the dominant deformation mechanisms in low elongation to fracture, with an m-value of 0.3-0.4;

- High strain rate and low-temperature superplasticity are also reported but the elongation to fracture sufficiently reduced due to a low $\mathrm{m}$-value and the governing deformation mechanism, resulting in a solute drag creep mechanism and viscous glide dislocation. 


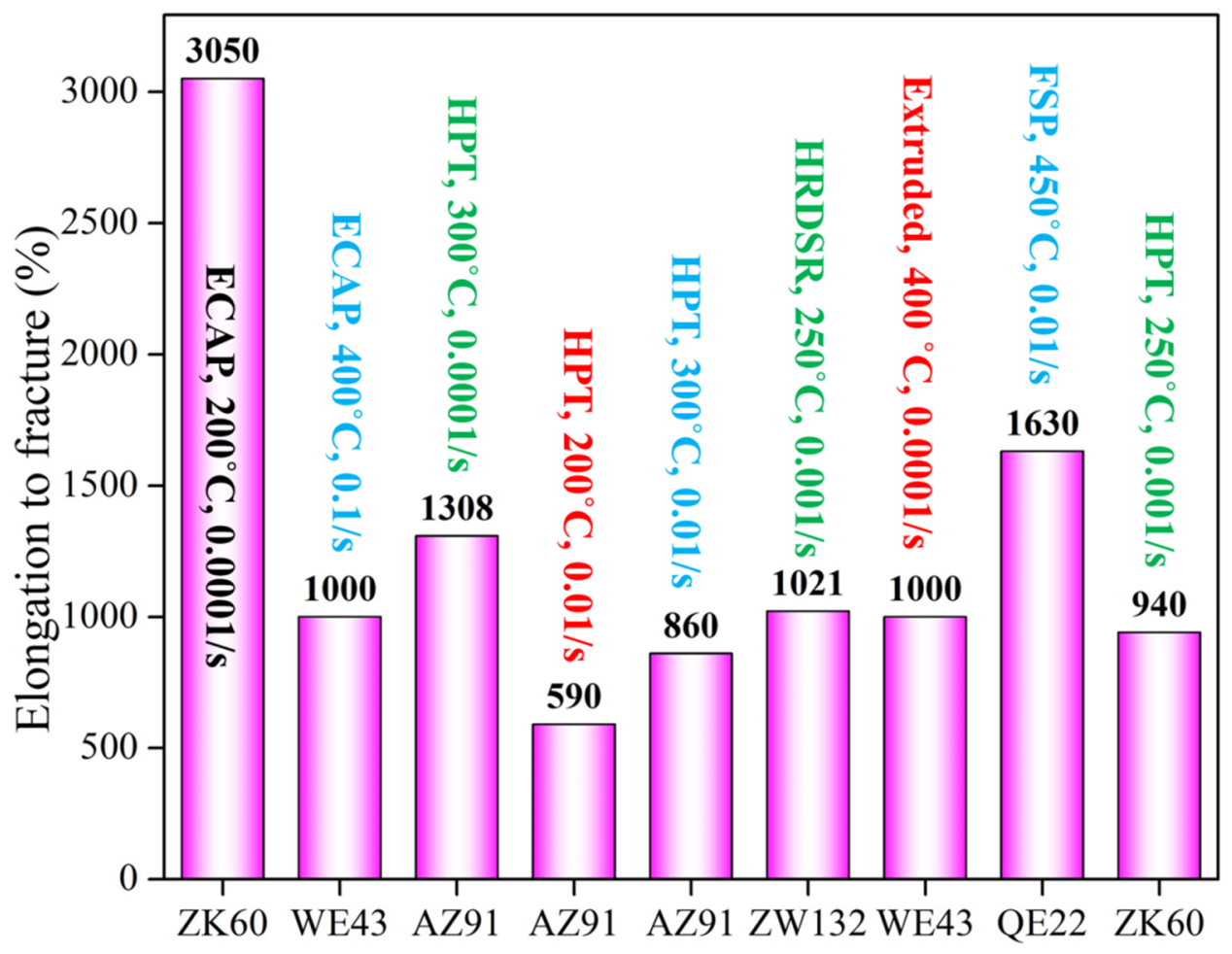

Figure 3. The processing methodologies, elongation to fracture, temperature and strain rate $[18,23,25,29,34,37,39]$.

\section{Thermal Stability and Q-Value}

During elevated temperature tensile testing, prolonged high-temperature exposure can cause abnormal grain growth, which can lead to structural and thermal instability. A temperature greater than $300{ }^{\circ} \mathrm{C}$ and a longer exposure time can significantly alter the morphology and volume fraction of precipitates. Especially, pure metals or single-phase alloys cannot exhibit superplasticity, owing to an increase in the grain size, which leads to premature failure. The increase in grain size can be impeded through precipitates under high-temperature loading. However, different precipitates have different melting temperatures; below the melting temperature, structural stability can be retained. It is reported that the coarsening of grains and $\beta-\mathrm{Mg}_{17} \mathrm{Al}_{12}$ precipitates in $\mathrm{AZ} 80 \mathrm{Mg}$ alloys impedes the elongation to fracture and hence deteriorates superplasticity [38]. Structure stability is correlated with $\mathrm{m}$-value, which controls the elongation to fracture and detains any abnormality during deformation; whereas, refined grain size is correlated to resist the damage development for low temperature and high strain rate superplasticity.

When Wang et al. [26] characterized the deformed specimen at grip section and gauge section of ED, TD and 45D specimens, they revealed that the grain size $(4.2 \mu \mathrm{m})$ in the grip section was similar to the extruded alloy (Figure 4a), while the grain size of gauge section in ED, TD and 45D specimens were finely recrystallized, comprising grain sizes of $3.2 \mu \mathrm{m}$, $2.8 \mu \mathrm{m}$ and $3.3 \mu \mathrm{m}$, respectively, as shown in Figure $4 \mathrm{~b}-\mathrm{d}$. Kim et al. [17] proposed that the 2nd phase particles were supportive to resist against grain growth and facilitated superplasticity, as shown in Figure 4e,f. Malik et al. [15] reported that $\mathrm{MgZn}_{2}$ phase particles have existed at $400{ }^{\circ} \mathrm{C}$, which impeded grain growth and supported superplasticity, as shown in Figure 5a,b. 
(a)

(c)
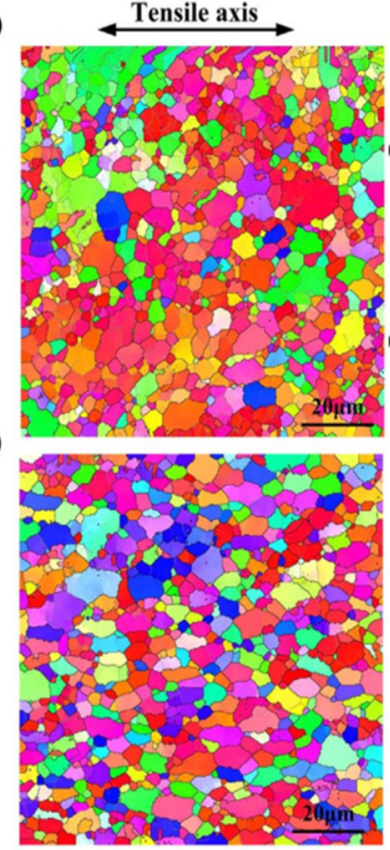

(b)
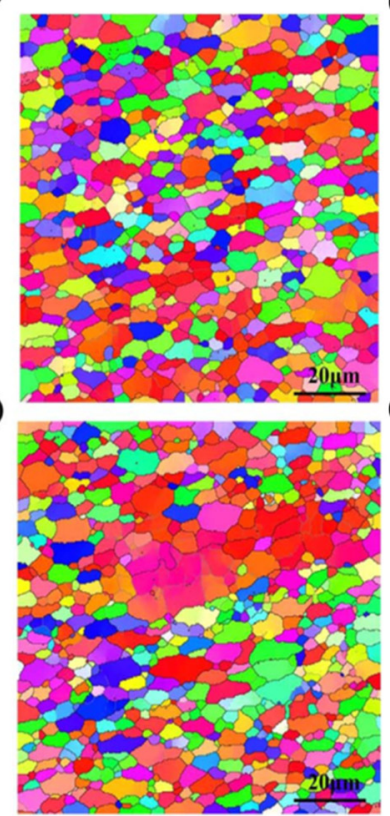

(e)

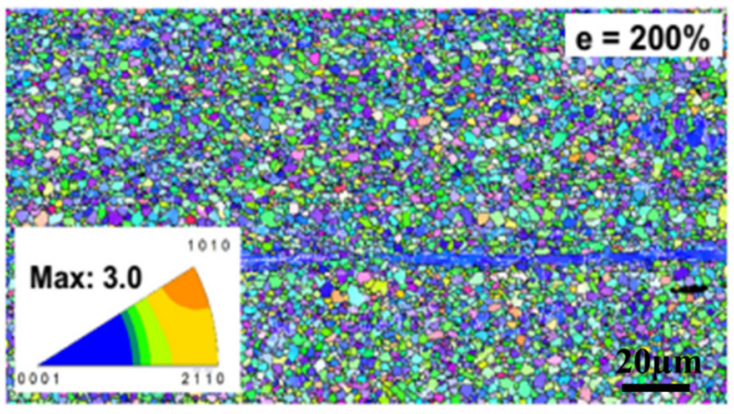

(f)

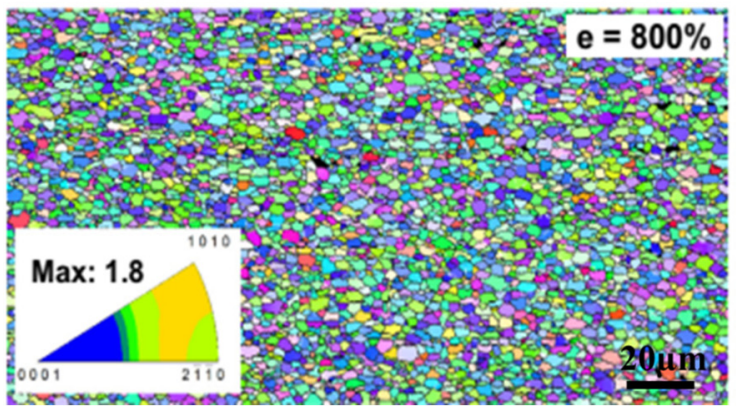

Figure 4. IPF maps of ZK60 Mg alloy: (a) grip section; (b-d) gauge section of ED, TD and 45D specimens, respectively, at a temperature of $275{ }^{\circ} \mathrm{C}$ [26]; (e,f) IPF maps of extruded ZK60 Mg alloys at elongation $200 \%$ and $800 \%$ at temperature of $250^{\circ} \mathrm{C}$ at a strain rate of $0.01 \mathrm{~s}^{-1}[17]$.
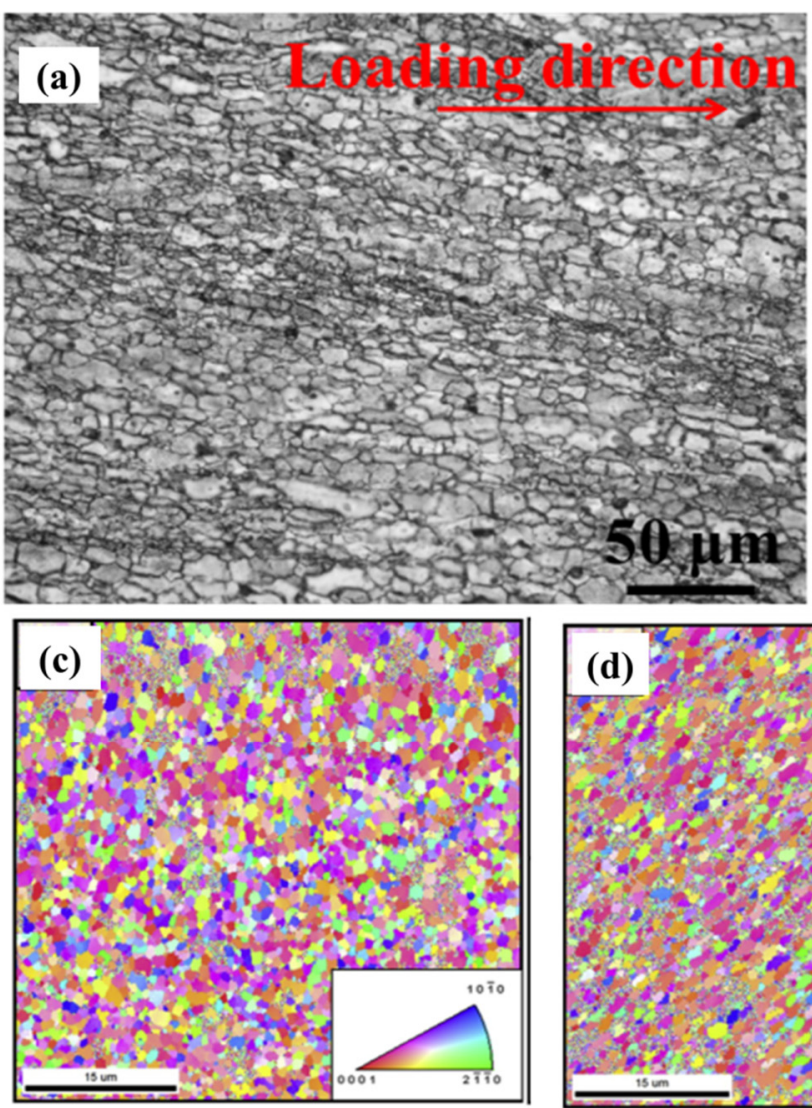
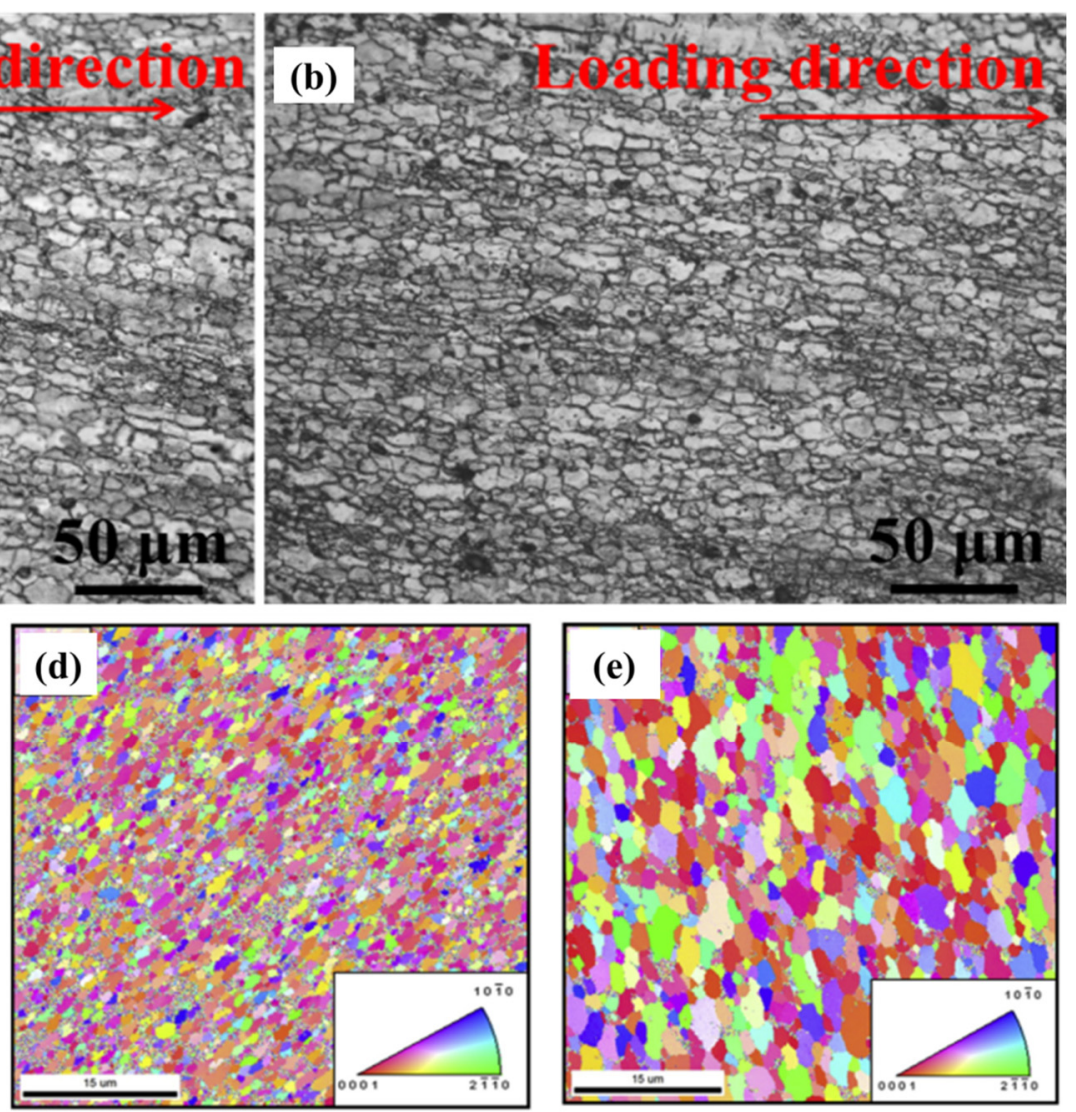

Figure 5. IPF maps and OM micrographs: (a,b) OM micrographs of extruded ZK60 at 350 and $400{ }^{\circ} \mathrm{C}$ [15]; (c) IPF maps of as received QE22 Mg alloy; (d,e) IPF maps at temperature $350{ }^{\circ} \mathrm{C}$ under strain rate of $0.01 \mathrm{~s}^{-1}$ and $0.003 \mathrm{~s}^{-1}$, respectively [39]. 
These EBSD and OM micrographs suggested that the grain size was thermally stable at elevated temperature tensile loading and could be attributed to 2nd phase particles. Similarly, a binary Mg-Gd alloy was prepared by Cizek et al. [40], who showed that the Mg-5Gd particles were supportive of impeding the grain size. However, in ternary alloys or higher incorporated metal alloys, such as brittle $\mathrm{Mg}_{24} \mathrm{Y}_{5}$, this resulted in $\mathrm{Mg}-\mathrm{Gd}-\mathrm{Y}-\mathrm{Zn}-\mathrm{Zr}$ being thermally stable at a temperature of $450{ }^{\circ} \mathrm{C}$, resisting grain growth and facilitating superplasticity [22].

Mohan et al. [41] reported that a high-volume fraction of $\beta-\mathrm{Mg}_{17} \mathrm{Al}_{12}$ precipitates was supportive in retaining microstructural thermal stability and facilitating superplasticity through the GBS mechanism. In other words, the higher structural and thermal stabilities can retain the GBS during higher elongation to fracture, suggesting that the precipitates that hinder the grain growth are the source of the GBS mechanism. Khan et al. [39] reported that the $\mathrm{Mg}_{12} \mathrm{Nd}$ eutectics and $\mathrm{Mg}_{12} \mathrm{Nd}_{2} \mathrm{Ag}$ precipitates were even thermally stable at a very high temperature of $650{ }^{\circ} \mathrm{C}$ and were contributing to impeding the grain growth, as shown in Figure 5c,d. However, they reported a grain growth at a lower strain rate of $0.003 \mathrm{~s}^{-1}$, as shown in Figure 5e. This aspect is mainly attributed to the longer exposure time and melting of the precipitates. Similarly, Kandlam et al. [21] revealed that the precipitates in WE43 $\mathrm{Mg}$ alloy were retained at $375^{\circ} \mathrm{C}$ and with a minor increase in temperature to $400{ }^{\circ} \mathrm{C}$, the precipitates were smeared out. Based on the precipitates and thermal stability of microstructure, a high elongation to fracture was achieved at $375{ }^{\circ} \mathrm{C}$ compared to $400{ }^{\circ} \mathrm{C}$.

Q-value is commonly known as the rate of deformation; the value close to 90 to $100 \mathrm{Kj} / \mathrm{mol}$ is related to grain boundary diffusion $\left(Q_{G B}\right)$ and that above $110 \mathrm{Kj} / \mathrm{mol}$ is related to lattice self-diffusion $Q_{L S}[15,29]$. The Q-value at a low temperature and a high strain rate increases due to an increasing strain-hardened index and hence results in low elongation to fracture. Thus, a Q-value $\sim 90 \mathrm{Kj} / \mathrm{mol}$ also facilitated the GBS phenomenon and enhanced superplasticity.

It can be concluded that:

- Thermal stability and structure stability due to precipitates and grain size support the uniform elongation without pre-mature failure;

- Different precipitates have different melting temperatures; thus, it is better to process the material at a temperature below the melting temperature of precipitates;

- Thermal stability and structure stability promote the GBS mechanism;

- Q-value is also an essential parameter. The higher the Q-value, the higher the deformation and the lower the m-value, thus resulting in lower elongation to fracture.

\section{Texture Evolution}

The high elongation to fracture at ambient temperature in $\mathrm{Mg}$ alloys is linked with a weak or tilted texture and a homogeneous fine grain size. However, a strong basal or fiber basal texture and bimodal grain structure in rolled/extruded $\mathrm{Mg}$ alloys restricts the large elongation to fracture; thus, it can be deduced that texture in $\mathrm{Mg}$ alloys can also promote superplasticity. The severe plastic deformation process usually produced highly misoriented fine grains, which promoted the GBS mechanism at high-temperature loading. Vale et al. [42] recommended that texture is not a significant parameter under high-temperature loading to control superplasticity. Similarly, Panicker et al. [43] proposed that texture does not have any influence on the superplasticity of AZ31 Mg alloy. In contrast to previous studies, Lin et al. [44] revealed that the texture effect can be different at low and high-temperature loading; they proposed that the texture was beneficial for low-temperature superplasticity, whilst at elevated temperature, the alloy did not have any significant influence on superplasticity. Malik et al. [15] also reported the transition of the texture from basal to non-basal, which affected the elongation to fracture.

Khan et al. [39] reported that the initial random texture was converted to the strong basal texture after the FSP process, as shown in Figure $6 a, b$, while texture distribution was similar to the FSPed form, and its intensity was the same at a temperature of $350{ }^{\circ} \mathrm{C}$ under a strain rate of $0.01 \mathrm{~s}^{-1}$ as shown in Figure $6 \mathrm{c}$. On the contrary, under the same 
temperature and comparatively low strain rate $\left(0.003 \mathrm{~s}^{-1}\right)$, they reported that $\{0002\}$ basal texture intensity ( $~ 8$ units) was very weak with random distribution compared to initial texture, as shown in Figure $6 \mathrm{~d}$. The weak texture was attributed to the grain rotation/grain rearrangement during the GBS mechanism.

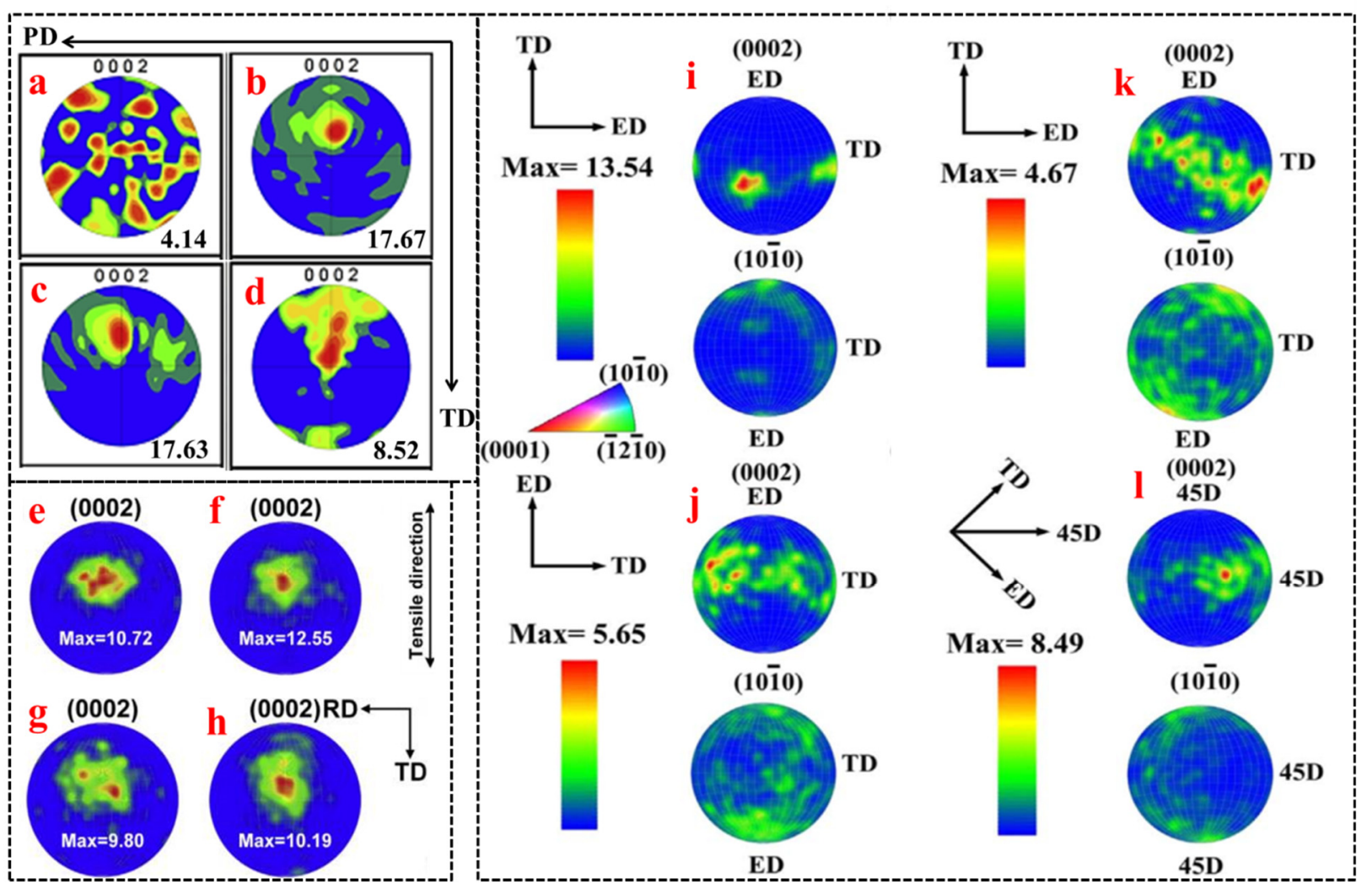

Figure 6. Pole figure analysis of different alloys: (a) QE22 Mg alloy in as received form; (b) as processed form; (c) under $350{ }^{\circ} \mathrm{C}$ at a strain rate of $0.01 \mathrm{~s}^{-1}$; (d) under $350{ }^{\circ} \mathrm{C}$ at a strain rate of $0.003 \mathrm{~s}^{-1}$ [39]; (e) pole figure of $\mathrm{Mg}-\mathrm{Al}-\mathrm{Zn}-\mathrm{Sn}$ at temperature $300{ }^{\circ} \mathrm{C}$ and a strain of $50 \%$; (f) at a strain of $100 \%$; (g) at a strain of $200 \%$; (h) at a strain of 300\% [45]; (i) grip section of ED specimen of ZK60 Mg alloy; (j) gauge section of TD; (k) gauge section of ED; (l) gauge section of 45D-sample [26].

Alvarez-Leal et al. [46] reported that the large coarse grains were refined during hightemperature tensile loading, which proposed that the grain refinement led to change in the texture during the recrystallization process; thus, based on the grain refinement after tensile loading, the texture might be changed and facilitate the GBS mechanism. Wang et al. [26] processed extruded ZK60 Mg alloy and studied the texture changes at a temperature of $275^{\circ} \mathrm{C}$ and a strain rate of $0.001 \mathrm{~s}^{-1}$. According to their results, the texture of extruded alloy and deformed specimen as grip section was the same, as shown in Figure 6i, whilst the ED, TD and 45D specimens showed a relatively random textures with a low texture intensity, as shown in Figure 6j-1. They also recommended that grain refinement during deformation changed the texture significantly and the change in the texture was due to the GBS mechanism control in the superplastic regime. Yu et al. [47] reported that, with the increase in the strain, the texture was rotated towards TD and the weakened texture was correlated with the GBS mechanism, as shown in Figure 5e-h. Similarly, Yang et al. [45] proposed that the texture was highly influenced and became weaker during deformation at elevated temperatures. In another study [22], a random texture of Mg-Gd-Y-Zn-Zr alloy was altered to the extruded fiber texture under high-temperature loading. Therefore, after a brief analysis, it is concluded that:

- During high temperature and high strain rate loading, dynamic recrystallization weakens the texture; 
- Texture effect is strain rate, temperature and exposure-time dependent;

- During high-temperature loading, in the early stages of deformation, the $<\mathrm{c}+\mathrm{a}>\mathrm{slip}$ activity alters the texture, which promotes the GBS phenomenon.

\section{Conclusions}

Grain structure and grain size have a significant influence on the m-value, $n$-value and elongation to fracture. For smaller grain size $\leq 10 \mu \mathrm{m}$, the m-value is very high $(\sim 0.5)$, and the Q-value is equal to the grain boundary self-diffusion, which enables the GBS and superplasticity. The record elongation to fracture of 3050\% is reported in ECAPprocessed ZK60 Mg alloy at a low temperature of $200{ }^{\circ} \mathrm{C}$, while extruded alloys have the highest elongation to fracture $>1000 \%$. In both cases, GBS was the governing deformation mechanism. High strain rate and low-temperature superplasticity are also reported but GBS and solute drag creep mechanism or viscous glide dislocation followed by GBS are the dominant deformations owing to low elongation to fracture, low $\mathrm{m}$-value $\sim 0.3-0.4$ and high Q-value. Thermal stability and structure stability also promote the GBS mechanism. Therefore, it is necessary to process $\mathrm{Mg}$ alloys slightly below the dissolution temperature of precipitate so that it can impede grain growth during longer exposure times. The effect of texture during deformation is strain rate, temperature and exposure-time dependent. In the early stages of deformation, the $<\mathrm{c}+\mathrm{a}>$ slip activity and dynamic recrystallization alter the texture, which promotes the GBS phenomenon. Thus, for perfect superplasticity at a low temperature and a high strain rate, a weak texture and highly dense precipitates require high dissolution temperatures, and the microstructure of equiaxed fine grain size is necessary.

Author Contributions: A.M. and U.M.C.: Investigation, Formal analysis, Data curation, Visualization, Writing —original draft. T.-S.J.: Supervision, Conceptualization, Writing-review \& editing. K.H.: Supervision, Conceptualization, Writing-review \& editing, Funding acquisition. All authors have read and agreed to the published version of the manuscript.

Funding: This research was funded by National Research Foundation (NRF) of South Korea, grant number (2020R1A2C1004720). And the APC was funded by National Research Foundation (NRF) of South Korea, grant number (2020R1A2C1004720).

Institutional Review Board Statement: Not applicable.

Informed Consent Statement: Not applicable.

Data Availability Statement: Not applicable.

Acknowledgments: This research was supported by the National Research Foundation (NRF) of South Korea (2020R1A2C1004720).

Conflicts of Interest: The authors declare that they have no known competing financial interests or personal relationships that could have appeared to influence the work reported in this paper.

\section{References}

1. Diqing, W.; Houbin, W.; Jiajun, H.; Yinglin, H.; Linsen, W.; Kangjin, F. Effect of the Secondary Phase on Mechanical and Damping Properties of Mg-Zn-Y-Si Alloy. Met. Mater. Int. 2021, 27, 838-842. [CrossRef]

2. Chaudry, U.M.; Hamad, K.; Kim, J.-G. On the ductility of magnesium based materials: A mini review. J. Alloys Compd. 2019, 792, 652-664. [CrossRef]

3. Wang, Q.; Jiang, B.; Chen, D.; Jin, Z.; Zhao, L.; Yang, Q.; Huang, G.; Pan, F. Strategies for enhancing the room-temperature stretch formability of magnesium alloy sheets: A review. J. Mater. Sci. 2021, 56, 12965-12998. [CrossRef]

4. Zou, D.L.; Zhen, L.; Zhu, Y.; Xu, C.Y.; Shao, W.Z.; Pang, B.J. Deformed microstructure evolution in AM60B Mg alloy under hypervelocity impact at a velocity of $5 \mathrm{kms}^{-1}$. Mater. Des. 2010, 31, 3708-3715. [CrossRef]

5. Malik, A.; Wang, Y.; Nazeer, F.; Khan, M.A.; Ali, T.; Ain, Q.T. Effect of pre-straining on twinning, texture and mechanical behavior of magnesium alloys A-review. J. Mater. Res. Technol. 2020, 9, 14478-14499. [CrossRef]

6. Malik, A.; Yangwei, W.; Huanwu, C.; Khan, M.A.; Nazeer, F.; Rui, A.; Jiawei, B.; Mingjun, W. Fracture behavior of twin induced ultra-fine grained ZK61 magnesium alloy under high strain rate compression. J. Mater. Res. Technol. 2019, 8, 3475-3486. [CrossRef]

7. Park, W.-W.; You, B.-S.; Lee, H.-R. Precipitation hardening and microstructures of rapidly solidified $\mathrm{Mg}-\mathrm{Zn}-\mathrm{Ca}-\mathrm{X}$ alloys. Met. Mater. Int. 2002, 8, 135. [CrossRef] 
8. Chaudry, U.M.; Tekumalla, M.; Gupta, M.; Jun, T.S.; Hamad, K. Designing highly ductile magnesium alloys: Current status and future challenges. Crit. Rev. Solid State Mater. Sci. 2021, 1-88. [CrossRef]

9. Yim, C.D.; Moon, Y.M.; You, B.S.; Na, Y.S.; Bae, J.S. Microstructural change in gravity cast Mg-Ni alloys with Ni contents. Met. Mater. Int. 2004, 10, 605. [CrossRef]

10. Chaudry, U.M.; Kim, T.H.; Park, S.D.; Kim, Y.S.; Hamad, K.; Kim, J.-G. Effects of calcium on the activity of slip systems in AZ31 magnesium alloy. Mater. Sci. Eng. A 2019, 739, 289-294. [CrossRef]

11. Liu, F.; Liu, X.; Zhu, B.; Yang, H.; Xiao, G.; Hu, M. Influence of Microstructure and Mechanical Properties on Formability in High Strain Rate Rolled AZ31 Magnesium Alloy Sheets. Met. Mater. Int. 2021. [CrossRef]

12. Huang, Y.; Zhou, X.; Du, J. Microstructure, Thermal Conductivity and Mechanical Properties of the Mg-Zn-Sb Ternary Alloys. Met. Mater. Int. 2021, 27, 4477-4486. [CrossRef]

13. Malik, A.; Wang, Y.; Huanwu, C.; Nazeer, F.; Ahmed, B.; Khan, M.A.; Mingjun, W. Constitutive analysis, twinning, recrystallization, and crack in fine-grained ZK61 Mg alloy during high strain rate compression over a wide range of temperatures. Mater. Sci. Eng. A 2020, 771, 138649. [CrossRef]

14. Chaudry, U.M.; Hamad, K.; Ko, Y.G. Effect of calcium on the superplastic behavior of AZ31 magnesium alloy. Mater. Sci. Eng. A 2021, 815, 140874. [CrossRef]

15. Malik, A.; Wang, Y.; Huanwu, C.; Bhatti, T.M.; Nazeer, F. Superplastic behavior of fine-grained extruded ZK61 Mg alloy. Results Phys. 2021, 20, 103731. [CrossRef]

16. Álvarez-Leal, M.; Orozco-Caballero, A.; Carreño, F.; Ruano, O.A. Superplasticity in a commercially extruded ZK30 magnesium alloy. Mater. Sci. Eng. A 2018, 710, 240-244. [CrossRef]

17. Kim, B.; Kim, J.C.; Lee, S.; Lee, K.-S.; Lee, J.G.; Park, S.S. High-strain-rate superplasticity of fine-grained Mg-6Zn-0.5 Zr alloy subjected to low-temperature indirect extrusion. Scr. Mater. 2017, 141, 138-142. [CrossRef]

18. Watanabe, H.; Mukai, T.; Ishikawa, K.; Mohri, T.; Mabuchi, M.; Higashi, K. Superplasticity of a particle-strengthened WE43 magnesium alloy. Mater. Trans. 2001, 42, 157-162. [CrossRef]

19. Ruano, O.A.; Álvarez-Leal, M.; Orozco-Caballero, A.; Carreño, F. Large elongations in WE54 magnesium alloy by solute-drag creep controlling the deformation behavior. Mater. Sci. Eng. A 2020, 791, 139757. [CrossRef]

20. Hua, Z.-M.; Wang, B.-Y.; Wang, C.; Zhang, H.-M.; Du, C.-F.; Li, Y.-J.; Zha, M.; Ma, P.-K.; Yang, Z.-Z.; Wang, H.-Y. Solute segregation assisted superplasticity in a low-alloyed Mg-Zn-Ca-Sn-Mn alloy. Materialia 2020, 14, 100918. [CrossRef]

21. Kandalam, S.; Sabat, R.; Bibhanshu, N.; Avadhani, G.; Kumar, S.; Suwas, S. Superplasticity in high temperature magnesium alloy WE43. Mater. Sci. Eng. A 2017, 687, 85-92. [CrossRef]

22. Sun, C.; Liu, H.; Wang, X.; Hu, X.; Jiang, S. Microstructure evolution during superplastic deformation process and its impact on superplastic behavior of a Mg-Gd-Y-Zn-Zr alloy. Mater. Charact. 2021, 172, 110879. [CrossRef]

23. Vávra, T.; Minárik, P.; Veselý, J.; Král, R. Excellent superplastic properties achieved in Mg-4Y-3RE alloy in high strain rate regime. Mater. Sci. Eng. A 2020, 784, 139314. [CrossRef]

24. Kim, W.; Kim, M.; Wang, J. Superplastic behavior of a fine-grained ZK60 magnesium alloy processed by high-ratio differential speed rolling. Mater. Sci. Eng. A 2009, 527, 322-327. [CrossRef]

25. Kwak, T.Y.; Kim, W.J. Superplastic behavior of an ultrafine-grained Mg-13Zn-1.55 Y alloy with a high volume fraction of icosahedral phases prepared by high-ratio differential speed rolling. J. Mater. Sci. Technol. 2017, 33, 919-925. [CrossRef]

26. Wang, H.-Y.; Rong, J.; Yu, Z.-Y.; Zha, M.; Wang, C.; Yang, Z.-Z.; Bu, R.-Y.; Jiang, Q.-C. Tensile properties, texture evolutions and deformation anisotropy of as-extruded $\mathrm{Mg}-6 \mathrm{Zn}-1 \mathrm{Zr}$ magnesium alloy at room and elevated temperatures. Mater. Sci. Eng. A 2017, 697, 149-157. [CrossRef]

27. Zhou, M.; Morisada, Y.; Fujii, H.; Wang, J.-Y. Pronounced low-temperature superplasticity of friction stir processed Mg-9Li-1Zn alloy. Mater. Sci. Eng. A 2020, 780, 139071. [CrossRef]

28. Figueiredo, R.B.; Langdon, T.G. Achieving superplastic properties in a ZK10 magnesium alloy processed by euqal-channel angular pressing. J. Mater. Res. Technol. 2017, 6, 129-135. [CrossRef]

29. Al-Zubaydi, A.S.; Zhilyaev, A.P.; Wang, S.C.; Reed, P.A. Superplastic behaviour of AZ91 magnesium alloy processed by highpressure torsion. Mater. Sci. Eng. A 2015, 637, 1-11. [CrossRef]

30. Xing, J.; Soda, H.; Yang, X.; Miura, H.; Sakai, T. Ultra-fine grain development in an AZ31 magnesium alloy during multi-directional forging under decreasing temperature conditions. Mater. Trans. 2005, 46, 1646-1650. [CrossRef]

31. Kai, M.; Horita, Z.; Langdon, T.G. Developing grain refinement and superplasticity in a magnesium alloy processed by highpressure torsion. Mater. Sci. Eng. A 2008, 488, 117-124. [CrossRef]

32. Lapovok, R.; Thomson, P.F.; Cottam, R.; Estrin, Y. Processing routes leading to superplastic behaviour of magnesium alloy ZK60. Mater. Sci. Eng. A 2005, 410, 390-393. [CrossRef]

33. Miura, H.; Yu, G.; Yang, X. Multi-directional forging of AZ61Mg alloy under decreasing temperature conditions and improvement of its mechanical properties. Mater. Sci. Eng. A 2011, 528, 6981-6992. [CrossRef]

34. Figueiredo, R.B.; Langdon, T.G. Record superplastic ductility in a magnesium alloy processed by equal-channel angular pressing. Adv. Eng. Mater. 2008, 10, 37-40. [CrossRef]

35. Torbati-Sarraf, S.A.; Langdon, T.G. Properties of a ZK60 magnesium alloy processed by high-pressure torsion. J. Alloys Compd. 2014, 613, 357-363. [CrossRef] 
36. Figueiredo, R.B.; Langdon, T.G. Developing superplasticity in a magnesium AZ31 alloy by ECAP. J. Mater. Sci. 2008, 43, 7366-7371. [CrossRef]

37. Torbati-Sarraf, S.A.; Alizadeh, R.; Mahmudi, R.; Langdon, T.G. Evaluating the flow properties of a magnesium ZK60 alloy processed by high-pressure torsion: A comparison of two different miniature testing techniques. Mater. Sci. Eng. A 2017, 708, 432-439. [CrossRef]

38. Wang, W.; Han, P.; Peng, P.; Guo, H.; Huang, L.; Qiao, K.; Hai, M.; Yang, Q.; Wang, H.; Wang, K. Superplastic deformation behavior of fine-grained AZ80 magnesium alloy prepared by friction stir processing. J. Mater. Res. Technol. 2020, 9, 5252-5263. [CrossRef]

39. Khan, F.; Panigrahi, S. Achieving excellent superplasticity in an ultrafine-grained QE22 alloy at both high strain rate and low-temperature regimes. J. Alloys Compd. 2018, 747, 71-82.

40. Č́̌̌̌̌ek, J.; Hruška, P.; Vlasák, T.; Vlček, M.; Janeček, M.; Minárik, P.; Krajňák, T.; Šlapáková, M.; Dopita, M.; Kužel, R.; et al. Microstructure development of ultra fine grained $\mathrm{Mg}-22 \mathrm{wt} \% \mathrm{Gd}$ alloy prepared by high pressure torsion. Mater. Sci. Eng. A 2017, 704, 181-191. [CrossRef]

41. Mohan, A.; Yuan, W.; Mishra, R. High strain rate superplasticity in friction stir processed ultrafine grained Mg-Al-Zn alloys. Mater. Sci. Eng. A 2013, 562, 69-76. [CrossRef]

42. del Valle, J.A.; Ruano, O.A. Separate contributions of texture and grain size on the creep mechanisms in a fine-grained magnesium alloy. Acta Mater. 2007, 55, 455-466. [CrossRef]

43. Panicker, R.; Chokshi, A.; Mishra, R.; Verma, R.; Krajewski, P. Microstructural evolution and grain boundary sliding in a superplastic magnesium AZ31 alloy. Acta Mater. 2009, 57, 3683-3693. [CrossRef]

44. Lin, H.; Huang, J.; Langdon, T. Relationship between texture and low temperature superplasticity in an extruded AZ31 Mg alloy processed by ECAP. Mater. Sci. Eng. A 2005, 402, 250-257. [CrossRef]

45. Yang, Q.; Feng, A.; Xiao, B.; Ma, Z. Influence of texture on superplastic behavior of friction stir processed ZK60 magnesium alloy. Mater. Sci. Eng. A 2012, 556, 671-677. [CrossRef]

46. Álvarez-Leal, M.; Carreño, F.; Orozco-Caballero, A.; Rey, P.; Ruano, O.A. High Strain Rate Superplasticity of WE54 Mg Alloy after Severe Friction Stir Processing. Metals 2020, 10, 1573. [CrossRef]

47. Yu, Z.P.; Yan, Y.H.; Yao, J.; Wang, C.; Zha, M.; Xu, X.Y.; Liu, Y.; Wang, H.Y.; Jiang, Q.C. Effect of tensile direction on mechanical properties and microstructural evolutions of rolled $\mathrm{Mg}$-Al-Zn-Sn magnesium alloy sheets at room and elevated temperatures. J. Alloys Compd. 2018, 744, 211-219. [CrossRef] 